\title{
Immunological Effects of Refolded Human Soluble BAFF Synthesized in Escherichia coli on Murine B Lymphocytes In Vitro and In Vivo
}

\author{
Meng CAO*, Long $\mathrm{CHEN}^{*, \dagger}$, Xiao Xiao SHAN*, , and Shuang Quan ZHANG* \\ *Jiangsu Province Key Laboratory for Molecular and Medical Biotechnology, College of Life Sciences, Nanjing Normal \\ University; and †Jiangsu Engineering Research Center for Biomedical Function Materials, Nanjing 210097, P.R. China
}

\begin{abstract}
The $B$ cell activating factor of the TNF family (BAFF, also known as BLyS, TALL1 , THANK, and zTNF4) is an important survival factor for B lymphocytes. Our previous study has demonstrated that the final purified material of human soluble BAFF (refolded hsBAFF) synthesized in Escherichia coli is biologically active in a validated induced human $B$ lymphocyte proliferation bioassay. In this study, the administration of refolded hsBAFF to isolated mouse B lymphocytes and mice was carried out to study the immunological effects of hsBAFF on in vitro and in vivo $B$ lymphocytes. The results showed that splenic B lymphocyte proliferation significantly increased after hsBAFF administration (in vitro 1, $2,3,5 \mathrm{\mu g} / \mathrm{ml}$ and in vivo $0.01,0.5,1.0 \mathrm{mg} / \mathrm{kg}$ body mass). An oppositely elevated immune response of B lymphocyte to LPS stimulation after hsBAFF
\end{abstract}

administration $(1,2.5,5 \mu \mathrm{g} / \mathrm{ml})$ and a significantly elevated change after treatment with hsBAFF and costimulation with anti-lgM $(2.5 \mu \mathrm{g} / \mathrm{ml})$ was observed in vitro, respectively. A similar change existed also in hsBAFF-treated mice on the 8th postexperiment day, but the value with anti-IgM alone didn't increase compared to normal control in vitro. We found that the treatment of mice with hsBAFF resulted in a developmental maturation of $T 1$ B lymphocytes to $T 2$ and mature $B$ lymphocytes by detecting distributions of splenic $\mathrm{CD} 21^{\text {lo }}$ with $\mathrm{CD} 45 \mathrm{R} / \mathrm{B} 220^{+}$and $\mathrm{CD} 21^{\mathrm{hi}}$ with $\mathrm{CD} 45 \mathrm{R} / \mathrm{B} 220^{+}$subsets. These results suggest that the refolded hsBAFF synthesized in Escherichia coli may enhance immune responses in the body by regulating the proliferation, differentiation, and immune response of $B$ lymphocytes. [The Japanese Journal of Physiology 55: 221-227, 2005]

Key words: human soluble BAFF, B lymphocyte, proliferation, immune response, differentiation.

The TNF family ligand B cell activating factor belonging to the TNF family (BAFF), also known as BLyS, TALL-1, THANK, zTNF4, and TNFSF13b, is synthesized as a 285-amino acid type II transmembrane protein and exists in membrane and in cleaved 152-amino acid soluble forms [1-4]. Reports have been accumulated that BAFF enhances B lymphocyte survival in vitro and emerges as a key regulator of peripheral B lymphocyte populations in vivo, leading to increases in serum immunoglobulin levels $[1,3]$. Further evidence of the involvement of BAFF in the stimulation of B lymphocyte growth and differentia- tion into plasma cells also comes from BAFF transgenic mice. These animals express large numbers of B lymphocytes and high levels of circulating immunoglobulins [5-7]. Studies on BAFF-deficient mice or individuals display the identification of soluble BAFF that may have therapeutic applications in B cell related disease states, such as single IgA, IgG, and IgM deficiencies and common variable immunodeficiency (CVID). In many of these disease states, the treatment of choice is the parenteral administration of immunoglobulin. However, B cell expansion and differentiation by means of BAFF treatment could provide

Received on Aug 28, 2005; accepted on Oct 28, 2005; released online on Oct 29, 2005; DOI: 10.2170/jjphysiol.R2130 Correspondence should be addressed to: Long Chen, College of Life Sciences, Nanjing Normal University, 122 Nanjing Ninghai Road, Nanjing 210097, Jiangsu, P.R. China. Tel: +86-25-83598216, Fax: +86-25-83598723, E-mail: Ichen@njnu.edu.cn 
a unique alternative to the conventional therapy of parenteral immunoglobulin $[8,9]$. Such data demonstrate that BAFF may play a major role in regulating B lymphocytes and in providing therapeutic applications in B lymphocyte related disease states. Further, some studies have demonstrated that an administration of BAFF results in a trend toward splenic B lymphocyte population expansion and differentiation (relative number and progression to a more mature form) and elevates the number of $\mathrm{CD} 45 \mathrm{R}^{+} / \mathrm{ThB}(\mathrm{Ly} 6 \mathrm{D})^{+} \mathrm{B}$ lymphocytes, a phenotype characteristic of terminally differentiated plasma cells $[1,8]$, suggesting that BAFF induces a functional maturation of immature B lymphocytes to mature cells [10].

The human soluble B cell activating factor belonging to the TNF family (hsBAFF), a recombinant form of the extracellular domain of BAFF, is expressed in Escherichia coli BL21 (DE3) by the constructed recombinant plasmid pET30a(+)-hsBAFF. Previous studies in our group have demonstrated that the final purified material (refolded hsBAFF) was biologically active in a validated induced human B lymphocyte proliferation bioassay [11]. The purpose of the present work was to further analyze the effects of refolded hsBAFF on the immune function activities of in vitro and in vivo splenic B lymphocytes as well as the distribution and differentiation of in vivo splenic B lymphocyte subsets to better understand the diverse functions of hsBAFF on enhancing immunity.

\section{MATERIALS AND METHODS}

Reagents. Anti-CD19 magnetic fluorobeads-B was obtained from One Lambda (Canoga Park, CA, USA). Mouse monoclonal antibodies (mAbs) of phycoerythrin (PE)-conjugated anti-CD45R/B220 and fluorescein isothiocyanate (FITC)-conjugated antiCD21 were from BD PharMingen (San Jose, CA, USA). RPMI 1640 Medium was from Gibco (Rockville, MD, USA). Standard hsBAFF was from PeproTech EC Ltd. (USA). NCS (neonatal cattle serum) was from Hangzhou Sijiqing Co. (Hangzhou, China), and 3-[4,5-dimethylthiazol-2-yl]-2,5-diphenyltetrazolium bromide (MTT), goat antimouse IgM, lipopolysaccharide (LPS), and paraformaldehyde were from Sigma Chemical Co. (St. Louis, MO, USA). Other chemicals were purchased from local commercial sources and were of analytical grade quality.

Preparation of recombinant hsBAFF protein. In brief, the constructed recombinant plasmid pET30a $(+)$-hsBAFF was transformed into competent
Escherichia coli BL21 (DE3). The bacteria were cultured in LB medium to a density of $\mathrm{OD}_{600}=0.6$, then induced for the expression of the recombinant protein via isopropyl- $\beta$-D-thiogalacto-pyranoside (IPTG). After induction, the resulting insoluble bodies were separated from cellular debris by centrifugation and solubilized with $8 \mathrm{M}$ urea. Then a rapid and simple oncolumn refolding procedure was developed. It was applied, and the refolded hsBAFF was purified by anion exchange. The purified final product was $>98 \%$ pure by SDS-PAGE stained with Coomassie Brilliant Blue $\mathrm{R}-250$. The renatured protein displayed its immunoreactivity with the antibodies to BAFF protein by Western blotting. The expression and in vitro refolding of hsBAFF resulted in the production of an active molecule in a yield of $15 \mathrm{mg} / l$ flask cultivation [11].

Animals. Sixteen ICR mice, 8 males and 8 females, each weighing 30-35 g, were obtained from the Laboratory Animal Center of Nanjing Medical University, Nanjing, China. The mice were housed at room temperature $\left(20-25^{\circ} \mathrm{C}\right)$ and subjected to a $12-\mathrm{h}$ light and 12-h dark cycle under conventional barrier protection and handled in accordance with the Animal Experimentation, which complies with guidelines for the care and use of animals for scientific purposes. Free access to water and food was allowed during the experimental period. All the mice were randomly divided into four groups: one normal control group $(n=4)$ and three hsBAFF treatment groups $(n=4,4,4)$. The mice in the treatment groups were given an abdominal cavity injection of refolded hsBAFF solution, which was diluted with phosphate-buffered saline (PBS, $\mathrm{pH}$ 7.4) at a dosage of $0.01,0.5,1.0 \mathrm{mg} / \mathrm{kg}$ body weight once a day for more than 8 days, respectively. The mice in the control group received abdominal injections of PBS at the same dose and frequency.

Isolation of splenic cells. On the 8th day after the refolded hsBAFF administration, the animals from each group were sacrificed via cervical dislocation to collect spleens under sterile conditions. Each spleen was minced into pieces with dissecting scissors, followed by further grinding and filtering through sterilized nylon membranes and washing in Hank's solution ( $\mathrm{pH} 7.2)$ via two centrifugations at $1,500 \mathrm{r} / \mathrm{min}$ for 5 min after the erythrocytes were dissolved with $0.85 \%$ amchlor solution. After that, the freshly isolated cells were splenic cells. Furthermore, splenic cells from healthy mice were isolated as described for the experiment of B lymphocytes in vitro.

Assay for B lymphocyte proliferation and immune response. B lymphocytes of $>97 \%$ purity 
A

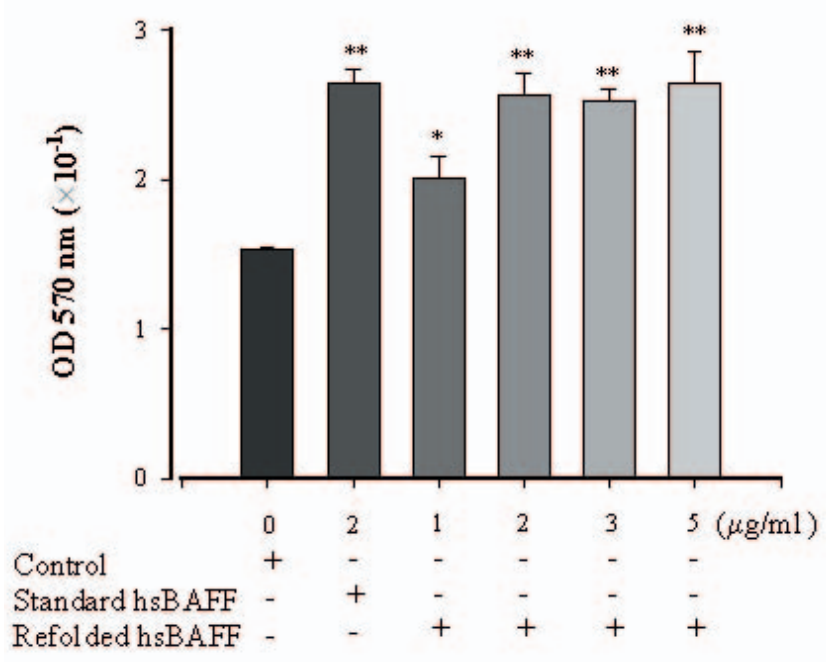

Fig. 1. Effects of refolded hsBAFF on in vitro murine splenic $B$ lymphocyte proliferation and its immune response to LPS stimulation. B lymphocytes of splenic cells from healthy mice were isolated by anti-CD19 magnetic fluorobeads. B lymphocyte proliferation after exposure to standard hsBAFF and refolded hsBAFF, respectively $(\mathbf{A})$,

were isolated from splenic cell suspensions by the use of anti-CD19 magnetic fluorobeads, as described [1, $3]$, then resuspended and diluted to $1 \times 10^{5}$ cells $/ \mathrm{ml}$ and cultured in RPMI 1640 medium containing 10\% $\mathrm{NCS}$ and $100 \mathrm{U} / \mathrm{ml}$ penicillin/streptomycin.

The effects of refolded hsBAFF administration on the proliferation and immune response of in vitro $\mathrm{B}$ lymphocytes were first evaluated. For B lymphocyte proliferation assay, the isolated B lymphocytes from healthy mice were seeded at $0.1 \mathrm{ml} /$ well in 96-well flat-bottomed plates and randomly divided into a normal control group, a treatment group with standard hsBAFF $(2 \mu \mathrm{g} / \mathrm{ml})$, and 4 treatment groups with refolded hsBAFF $(1,2,3,5 \mu \mathrm{g} / \mathrm{ml}$, respectively) with a triplicate of each group. The cells in the control group received PBS at the same dose. The cultures were maintained for $72 \mathrm{~h}$ at $37^{\circ} \mathrm{C}$ with $5 \% \mathrm{CO}_{2}$ humidified air. Then $0.01 \mathrm{ml}(5 \mathrm{mg} / \mathrm{ml})$ of MTT reagent was added to each well and incubated for $4 \mathrm{~h}$. After the incubation, the incubation precipitates were dissolved with $0.1 \mathrm{ml}$ of SDS. The optical density (OD) values were measured by spectrophotometry at $570 \mathrm{~nm}$ with an ELx $800 \mathrm{Mi}-$ croplate Reader (Bio-Tek Instruments, Inc. Winooski, Vermont, USA).

For an in vitro B lymphocyte immune response assay, the isolated B lymphocytes were seeded in triplicate in 96-well flat-bottomed plates with/without $2.5 \mu \mathrm{g} / \mathrm{ml}$ of goat antimouse IgM, and the refolded

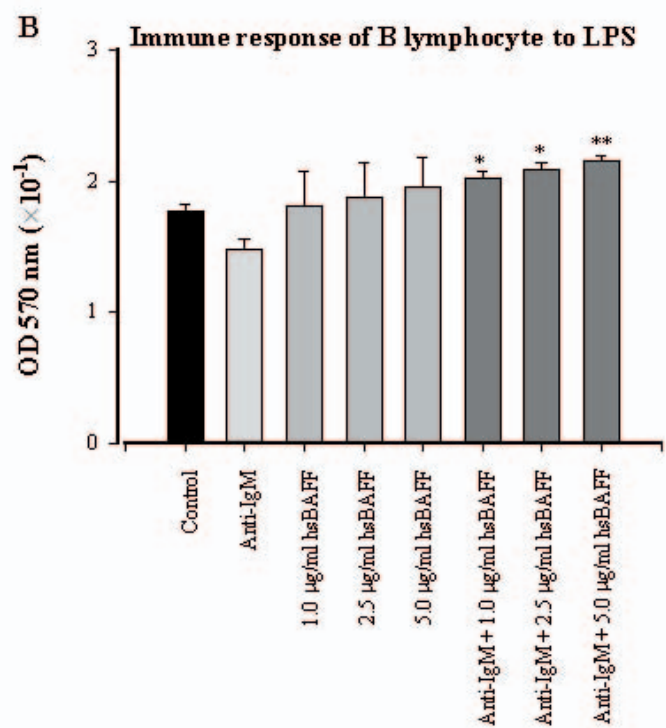

and immune response of B lymphocyte to LPS stimulation after pretreatment with refolded hsBAFF and costimulation with/without anti-IgM (B) were evaluated using an MTT assay. Results are presented as mean \pm SEM of $n=3$ for each group. ${ }^{\star} p<0.05,{ }^{* *} p<0.01$ vs. control group.

hsBAFF was added at the final concentrations of 1.0, $2.5,5.0 \mu \mathrm{g} / \mathrm{ml}$, respectively. After the cells were preincubated for $24 \mathrm{~h}, 10 \mu \mathrm{g} / \mathrm{ml}$ of LPS was added to each well and further incubated for $48 \mathrm{~h}$ at $37^{\circ} \mathrm{C}$. An MTT assay was then carried out as described above.

To understand the B lymphocyte proliferation and immune response of administered refolded hsBAFF in mice, freshly isolated B lymphocytes from the animals of each experiment group were seeded at $0.1 \mathrm{ml} /$ well in triplicate in the plates and incubated with or without $10 \mu \mathrm{g} / \mathrm{ml}$ of LPS for $72 \mathrm{~h}$ at $37^{\circ} \mathrm{C}$. Then an MTT assay was carried out.

Flow cytometry of B lymphocyte sorting. To elucidate distribution and differentiation of splenic $B$ lymphocyte subsets of administered refolded hsBAFF in mice, $100 \mu$ l suspension samples containing freshly isolated splenic cells that were resuspended at a density of more than $2 \times 10^{6}$ cells $/ \mathrm{ml}$ with PBS were incubated with mAbs of $1 \mu \mathrm{g}$ PE-conjugated anti-CD45R/ $\mathrm{B} 220$ and $1 \mu \mathrm{g}$ FITC-conjugated anti-CD21 in the dark for 30 min at $4{ }^{\circ} \mathrm{C}$, then washed 3 times with PBS and resuspended in $200 \mu \mathrm{l} \%$ paraformaldehyde for inactivation. The antibodies were replaced by PBS as negative controls. All samples were analyzed to detect the distributions of $\mathrm{CD} 21^{\text {lo }}$ with $\mathrm{CD} 45 \mathrm{R} / \mathrm{B} 220^{+}$and $\mathrm{CD} 21^{\text {hi }}$ with $\mathrm{CD} 45 \mathrm{R} / \mathrm{B} 220^{+}$subsets under a fluorescence-activated cell sorter (FACS) Vantage SE flow cytometer (Beton Dickinson, California, USA). Usu- 


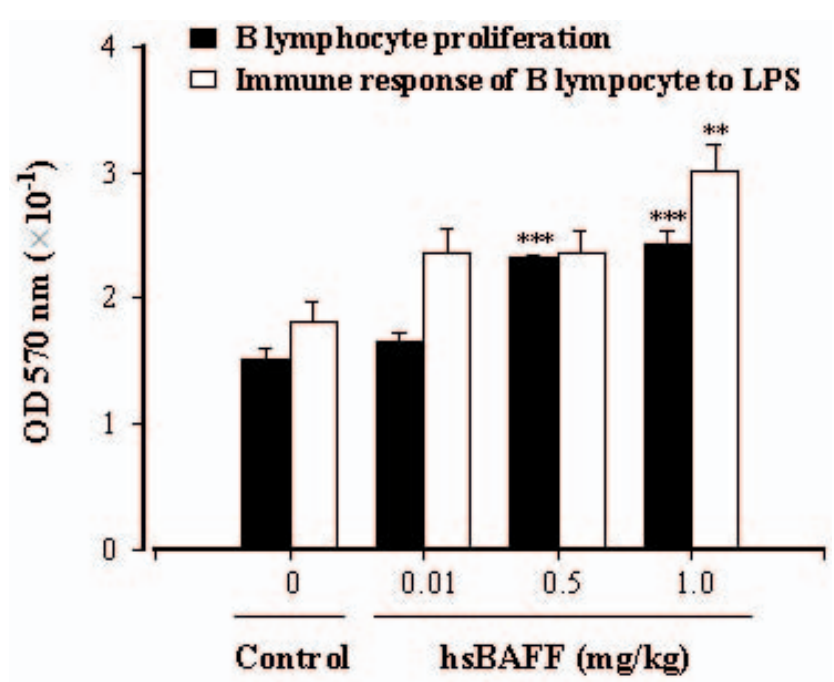

Fig. 2. Changes of B lymphocyte proliferation and its immune response to LPS stimulation in mice after refolded hsBAFF treatment. $B$ lymphocytes of splenic cells from mice were isolated by anti-CD19 magnetic fluorobeads. B lymphocyte proliferation and its immune responses to LPS stimulation in control and refolded hsBAFF-treated mice on the 8th postexperiment day were evaluated using an MTT assay. Results are presented as mean \pm SEM of $n=4$ for each group. ${ }^{\star *} p<0.01,{ }^{* \star *} p<0.001$ vs. control group.

ally, 20,000 events for each sample were acquired.

Statistical analysis. Data were expressed as the mean \pm SEM and analyzed by STATISTICA (Statsoft Inc., Tulsa, USA) followed by a Student's paired $t$-test. A $p$ value of 0.05 or less was considered to be statistically significant.

\section{RESULTS}

\section{Effects of refolded hsBAFF on the proliferation and immune response of murine splenic $B$ lymphocytes in vitro}

A significantly higher proliferation was observed in refolded hsBAFF-treated splenic B lymphocytes with dosages of $1 \mu \mathrm{g} / \mathrm{ml}(p<0.05), 2,3$, and $5 \mu \mathrm{g} / \mathrm{ml}(p<$ $0.01)$ compared to normal control cells. An in vitro proliferation effect between standard hsBFF-treated and refolded hsBAFF-treated cells with a final concentration of $2 \mu \mathrm{g} / \mathrm{ml}$ was similar (Fig. 1A). As shown in Fig. 1B, refolded hsBAFF administration (1, 2.5, 5 $\mu \mathrm{g} / \mathrm{ml}$ ) resulted in an oppositely elevated immune response of B lymphocyte to LPS stimulation. A significantly elevated change after treatment with hsBAFF and costimulation with anti-IgM was observed concentration-dependently $(p<0.05, p<0.05$, and $p<$ 0.01 , respectively), but the value with anti-IgM alone didn't increase compared to normal control in vitro.
Effects of refolded hsBAFF on splenic $B$ lymphocyte proliferation and immune response in mice

As demonstrated in Fig. 2, splenic B lymphocyte proliferation in $0.01 \mathrm{mg} / \mathrm{kg}$ refolded hsBAFF-treated mice was similar to that in control animals. However, a dose-dependent increase of stronger splenic B lymphocyte proliferation with an elevation of refolded hsBAFF dosages was observed, and significantly higher values occurred in 0.5 and $1.0 \mathrm{mg} / \mathrm{kg}$ refolded hsBAFF-treated mice $(p<0.001)$ than in control mice. A greatly elevated immune response of B lymphocyte to LPS stimulation and a significantly higher value in 1.0 $\mathrm{mg} / \mathrm{kg}$ refolded hsBAFF-treated mice $(p<0.01)$ were observed compared to control mice.

\section{Effects of refolded hsBAFF on CD21 ${ }^{10}$ with CD45R/B220 ${ }^{+}$and $C D 21^{\text {hi }}$ with CD45R/B220 ${ }^{+}$B lymphocytes in mice}

To understand the immunity of B lymphocytes in mice after refolded hsBAFF treatment, two-color mAbs, which are used to distinguish $\mathrm{CD} 21^{\text {10 }}$ with $\mathrm{CD} 45 \mathrm{R} / \mathrm{B} 220^{+}$and $\mathrm{CD} 21^{\text {hi }}$ with $\mathrm{CD} 45 \mathrm{R} / \mathrm{B} 220^{+} \mathrm{B}$ lymphocytes, were conducted to detect the distributions of $\mathrm{CD} 21^{\text {lo }}$ with $\mathrm{CD} 45 \mathrm{R} / \mathrm{B} 220^{+}$and $\mathrm{CD} 21^{\mathrm{hi}}$ with $\mathrm{CD} 45 \mathrm{R} /$ $\mathrm{B} 220^{+}$subsets under a flow cytometry. As demonstrated in Fig. 3A, cells gated R1 appeared to be CD2 $1^{\text {1o }}$ with $\mathrm{CD} 45 \mathrm{R} / \mathrm{B} 220^{+}$B lymphocytes, and those gated $\mathrm{R} 2$ appeared to be $\mathrm{CD} 21^{\mathrm{hi}}$ with $\mathrm{CD} 45 \mathrm{R} / \mathrm{B} 220^{+} \mathrm{B}$ lymphocytes. Figure 3B showed that CD21 ${ }^{\text {hi }}$ with CD45R/ $\mathrm{B} 220^{+}$B lymphocytes (\%) in $0.01 \mathrm{mg} / \mathrm{kg}$ refolded hsBAFF-treated mice was close to that in control animals, but a following higher increase was observed, and significantly higher changes $(p<0.01)$ occurred in $0.5 \mathrm{mg} / \mathrm{kg}$ refolded hsBAFF-treated mice than in control mice. There were no significant differences between control mice and refolded hsBAFF-treated mice, though the $\mathrm{CD} 21^{\text {lo }}$ with $\mathrm{CD} 45 \mathrm{R} / \mathrm{B} 220^{+} \mathrm{B}$ lymphocytes $(\%)$ rose with a dosage increase of refolded hsBAFF treatment (Fig. 3C). Total CD45R/B220 ${ }^{+}$B lymphocytes (\%) were significantly higher in 0.5 and $1 \mathrm{mg} / \mathrm{kg}$ refolded hsBAFF-treated mice than in control mice ( $p<0.05$, Fig. 3D).

\section{DISCUSSION}

BAFF is a potent proliferative cytokine for the stimulation of the B lymphocyte. Early studies have indicated that the identification of soluble BAFF may have therapeutic applications in human B cell related disease states, such as isolated $\operatorname{IgA}, \operatorname{IgG}$, and IgM deficiencies; common variable immunodeficiency and other 
A
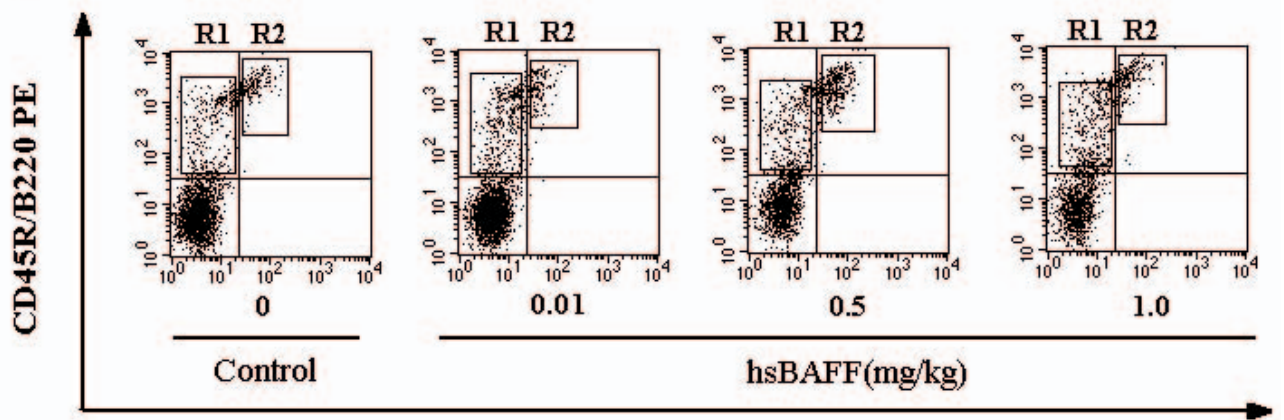

CD21 FITC
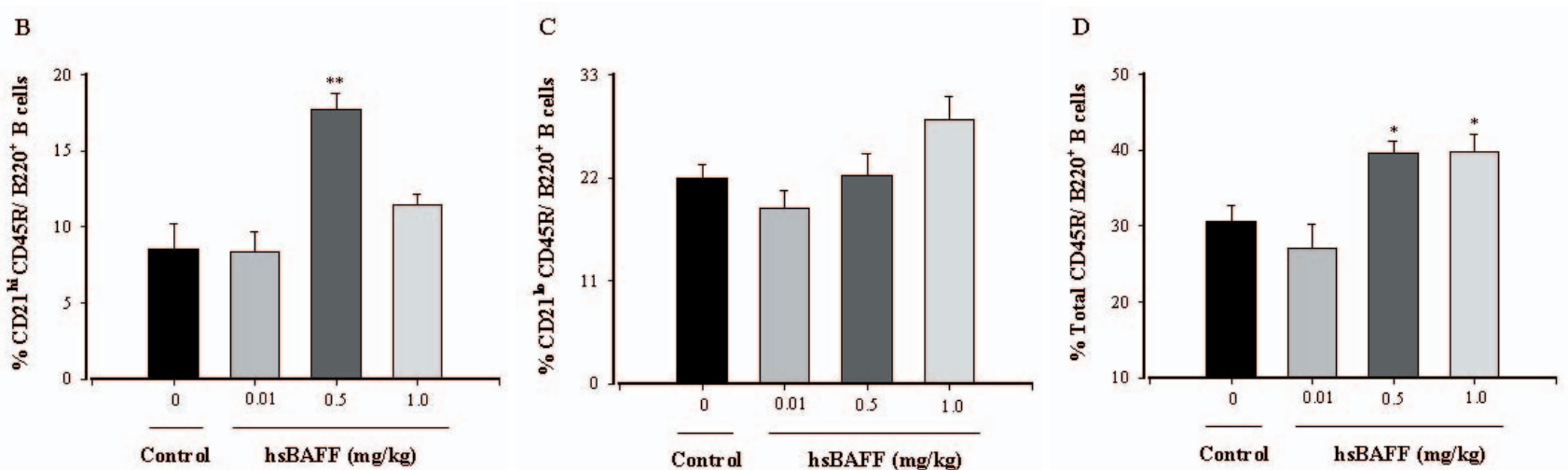

Fig. 3. Changes of splenic CD21 ${ }^{\text {lo }}$ with CD45R/B220+ and $\mathrm{CD}^{2} 1^{\text {hi }}$ with CD45R/B220+ subsets in mice after refolded hsBAFF treatment. A: B lymphocytes of splenic cells in mice from each group were sorted with two mAbs of FITCconjugated anti-CD21 and PE-conjugated anti-CD45R/ B220 and analyzed using flow cytometry. Gates R1 (CD21 $1^{\text {lo }}$ with $\left.\mathrm{CD} 45 \mathrm{R} / \mathrm{B} 220^{+}\right)$and $\mathrm{R} 2\left(\mathrm{CD} 21^{\mathrm{hi}}\right.$ with $\left.\mathrm{CD} 45 \mathrm{R} / \mathrm{B} 220^{+}\right)$

were indicated in each plot. B: Changes of $\mathrm{CD} 21^{\text {hi }}$ with CD45R/B220+ B lymphocytes (\%). C: Changes of CD21 $1^{10}$ with CD45R/B220+ B lymphocytes (\%). D: Changes of total CD45R/B220+ B lymphocytes (\%). Results are presented as mean \pm SEM of $n=4$ for each group. ${ }^{\star} p<0.05,{ }^{* *} p<0.01$ vs. control group.

panhypogammaglobulinemias, and X-linked immunodeficiency with increased $\operatorname{IgM}[8,11]$. Under these conditions, abnormal B cell function leads to global or specific hypoimmunoglobulinemia and/or decreased secretory immunoglobulin levels. In many of these disease states, the treatment of choice is the parenteral administration of immunoglobulin [8,9]. However, B lymphocyte expansion and differentiation resulted from BAFF treatment could provide a unique alternative to conventional parenteral immunoglobulin therapy. Thus BAFF, as a growth factor that promotes B lymphocyte proliferation and differentiation, is being developed to increase the production of endogenous immunoglobulins in patients with certain hypogammaglobulinemias. Refolded hsBAFF, a recombinant form of the extracelluar domain of BAFF, is expressed in Escherichia coli BL21 (DE3) by the constructed recombinant plasmid pET30a(+)-hsBAFF. Our previous studies have been demonstrated that refolded hsBAFF is biologically active in a validated induced human $B$

lymphocyte proliferation bioassay [11] and is able to enhance immune responses in the body by increasing $\mathrm{CD}^{+} \mathrm{T}$ lymphocyte function as well as NK cell activity [12]. To better understand the diverse functions of refolded hsBAFF and to provide important information for the design of a clinical application for refolded hsBAFF, we examined the effects of refolded hsBAFF on immune function activities of in vitro and in vivo murine splenic B lymphocytes as well as the distribution and differentiation of in vivo murine splenic $\mathrm{B}$ lymphocyte subsets.

In this study, our group showed that refolded hsBAFF synthesized in Escherichia coli significantly increased the proliferation of murine splenic B lymphocytes in vivo and in vitro. The finding is in agreement with previous studies that BAFF induces in vitro and in vivo B lymphocyte proliferation $[1,4]$. To further understand B lymphocyte immune activity of refolded hsBAFF administration in vitro and in vivo, we stimulated freshly isolated B lymphocytes from 


\section{CAO et al.}

splenic cells of each experiment with LPS. As a result, an oppositely elevated immune response of B lymphocyte to LPS stimulation after refolded hsBAFF administration $(1,2.5,5 \mu \mathrm{g} / \mathrm{ml})$ was observed in vitro; similar changes existed also in hsBAFF-treated mice on the 8th postexperiment day compared to normal control mice, revealing that the administration of refolded hsBAFF results in an elevated B lymphocyte immune response. Recently, some data suggest that BAFF deficiency or overexpression creates a state of immune imbalance that leads to a breakdown in tolerance and autoimmunity [13. 14]. BAFF gene knockout further reveals that BAFF is required for normal B lymphocyte development $[15,16]$. Taken together, these results demonstrate that BAFF plays a critical balance role in regulating the immune responses of $B$ lymphocytes in the body $[4,17]$.

Previous reports indicate that BAFF induces B lymphocyte proliferation when cultured with cells costimulated with anti-IgM $[1,3]$. In this study, a significantly elevated immune response of B lymphocyte to LPS stimulation after treatment with refolded hsBAFF and costimulation with anti-IgM was observed, but the value with anti-IgM alone didn't increase compared to normal control in vitro, suggesting that anti-IgM, as a priming agent, plays a potent role in B lymphocyte proliferation and thereby immune response in response to refolded BAFF. Some reports indicate that BAFF preferentially supports the survival of transitional type 2 (T2) and some marginal-zone (MZ) B lymphocyte subsets found solely in the spleen of normal mice. MZ B lymphocytes are highly sensitive to LPS stimulation and differentiate into mature plasma cells and secrete large quantities of antibodies in response to it [18]. Thus this observation obtained in our study also reveals that refolded hsBAFF may intensify the differentiation and potent immune activity of T2 and MZ B lymphocytes by costimulating with anti-IgM.

Recently, several functional and phenotypic B lymphocyte populations have been described in the spleen. These include the "transitional" immature B lymphocyte subsets [19]. The immature B lymphocytes characterized by two different phenotypes in the spleen can be distinguished by their surface marker expression into transitional type 1 (T1) B lymphocytes $\left(\mathrm{sIgM}^{\mathrm{hi}}, \mathrm{sIgD}^{\mathrm{lo}}, \mathrm{CD} 21^{\mathrm{lo}}, \mathrm{CD} 23^{-}, \mathrm{C} 1 \mathrm{qRp}^{+}\right.$, $\mathrm{B} 220^{+}$) and transitional type 2 (T2) B lymphocytes $\left(\mathrm{sIgM}^{\text {int }}, \mathrm{sIgD}^{\mathrm{hi}}, \mathrm{CD} 21^{\mathrm{hi}}, \mathrm{CD} 23^{+}, \mathrm{C} 1 \mathrm{qRp}^{+}, \mathrm{B} 220^{+}\right)$. Mature B lymphocytes have the same phenotype as immature T2 B lymphocytes, except that they no longer express C1qRp. T1 B lymphocytes are the precursors for T2 and mature B cells, and T2 B lymphocytes are the direct precursors of mature B lymphocytes [2022]. In the present study, our observations showed that an administration of refolded hsBAFF ( 0.5 and $1 \mathrm{mg} / \mathrm{kg}$ ) to mice resulted in an obvious elevation of total CD45R/B220+ B lymphocytes (\%) and CD21 $1^{\mathrm{hi}}$ with $\mathrm{CD} 45 \mathrm{R} / \mathrm{B} 220^{+} \mathrm{B}$ lymphocytes (\%) compared to control mice, indicating that refolded hsBAFF increases a developmental maturation of splenic T1 B lymphocytes $\left(\mathrm{CD} 21^{\text {lo }}\right.$ with $\left.\mathrm{CD} 45 \mathrm{R} / \mathrm{B} 220^{+}\right)$to $\mathrm{T} 2$ and mature B lymphocytes $\left(\mathrm{CD} 21^{\mathrm{hi}}\right.$ with $\left.\mathrm{CD} 45 \mathrm{R} / \mathrm{B} 220^{+}\right)$as well as a B lymphocyte population expansion, which is consistent with previous studies showing that BAFF results in a trend toward splenic B lymphocyte population expansion and differentiation $[1,8]$. Recent studies on BAFF-transgenic mice show increased numbers of T2 immature B lymphocytes and extended marginal zones with B lymphocytes in vivo. The vastly unequal expansion of these subsets, favoring strongly the $\mathrm{T} 2$ and MZ B lymphocyte compartments, indicates that an overexpression of BAFF directly or indirectly modifies the dynamics of the entire B lymphocyte maturation and differentiation pathway in BAFF-transgenic mice $[23,24]$. However, in BAFF-deficient mice, B lymphocyte development in the spleen up to the level of immature $\mathrm{T} 1$ seems to be normal. Immature $\mathrm{T} 2$ and marginal-zone B lymphocytes are nearly absent [22]. Such data further suggest that BAFF plays a key role in regulating a functional maturation of immature $\mathrm{B}$ lymphocytes to mature cells in the spleen [10].

In conclusion, refolded hsBAFF markedly induces in vitro B lymphocyte proliferation and immune response and enhances immune function in the body by inducing in vivo B lymphocyte proliferation and differentiation, increasing its immune response.

This work was supported by the Natural Science Fund from the Education Department of Jiangsu Province, China (No. 02KJB180003); the Research Program of Science and Technology Commission Foundation of Jiangsu Province, China (No. BK2005140); and the Nanjing Normal University High Technology Innovation Fund. We thank Dr. P. Cao for help and technical support in the preparation of refolded hsBAFF protein and Dr. L. Wang for technical support in flow cytometry.

\section{REFERENCES}

1. Moore PA, Belvedere O, Orr A, Pieri K, Lafleur DW, Feng P, Soppet D, Charters M, Gentz R, Parmelee D, Li Y, Galperina O, Giri J, Roschke V, Nardelli B, Carrell J, Sosnovtseva S, Greenfield W, Ruben SM, Olsen HS, Fikes J, and Hilbert DM: Blys: Member of the tumor necrosis factor family and B lymphocyte stimulator. Science 285: 260-263, 1999 


\section{Immunity of hsBAFF on B Lymphocytes}

2. Mukhopadhyay A, Ni J, Zhai Y, Yu GL, and Aggarwal BB: Identification and characterization of a novel cytokine, THANK, a TNF homologue that activates apoptosis, nuclear factor-kB, and $\mathrm{c}$-jun $\mathrm{NH}_{2}$-terminal kinase. J Biol Chem 274: 15978-15981, 1999

3. Schneider P, Mackay F, Steiner V, Hofmann K, Bodmer JL, Holler N, Ambrose C, Lawton P, Bixler S, Acha-Orbea $\mathrm{H}$, Valmori D, Romero P, Werner-Favre C, Zubler $\mathrm{RH}$, Browning $\mathrm{JL}$, and Tschopp J: BAFF, a novel ligand of the tumor necrosisfactor (TNF) family, stimulates B cell growth. J Exp Med 189: 1747-1756, 1999

4. Shu HB, Hu WH, and Johnson H: TALL-1 is a novel member of the TNF family that is down-regulated by mitogens. J Leukoc Biol 65: 680-683, 1999

5. Mackay F, Woodcock SA, Lawton P, Ambrose C, Baetscher M, Schneider P, Tschopp J, and Browning JL: Mice transgenic for BAFF develop lymphocytic disorders along with autoimmune manifestations. J Exp Med 190: 1697-1710, 1999

6. Gross JA, Johnston J, Mudri S, Enselman R, Dillon SR, Madden K, Xu W, Parrish-Novak J, Foster D, Lofton-Day C, Moore M, Littau A, Grossman A, Haugen H, Foley K, Blumberg $\mathrm{H}$, Harrison $\mathrm{K}$, Kindsvogel W, and Clegg $\mathrm{CH}$ : TACl and BCMA are receptors for a TNF homologue implicated in B-cell autoimmune disease. Nature 404 995-999, 2000

7. Khare SD, Sarosi I, Xia XZ, McCabe S, Miner K, Solovyev I, Hawkins N, Kelley M, Chang D, Van G, Ross L, Delaney J, Wang L, Lacey D, Boyle WJ, and Hsu $\mathrm{H}$ : Severe B lymphocyte hyperplasia and autoimmune disease in TALL-1 transgenic mice. Proc Natl Acad Sci USA 97: 3370-3375, 2000

8. Parry TJ, Riccobene TA, Strawn SJ, Williams R, Daoud R, Carrell J, Sosnovtseva S, Miceli RC, Poortman CM, Sekut L, Li Y, Fikes J, and Sung C: Pharmacokinetics and immunological effects of exogenously administered recombinant human B lymphocyte stimulator (BLyS) in mice. J Pharmacol Exp Ther 296: 396-404, 2001

9. Stewart DM, McAvoy MJ, Hilbert DM, and Nelson DL: B lymphocytes from individuals with common variable immunodeficiency respond to B lymphocyte stimulator (BLyS protein) in vitro. Clin Immunol 109: 137-143, 2003

10. Carsetti R, Rosado MM, and Wardemann H: Peripheral development of $\mathrm{B}$ cells in mouse and man. Immunol Rev 197: 179-191, 2004

11. Cao P, Mei JJ, Diao ZY, and Zhang SQ: Expression, refolding, and characterization of human soluble BAFF synthesized in Escherichia coli Protein Expr Purif 41: 199-206, 2005

12. Shan X, Chen L, Cao M, Xu L, and Zhang S: Effects of human soluble BAFF synthesized in Escherichia coli on CD4+ and CD8+ T lymphocytes as well as NK cells in mice. Physiol Res 55: in press, 2006 (prepressed in http://www.biomed.cas.cz/physiolres/prepress.htm)

13. Baker KP: BLyS-an essential survival factor for B cells: basic biology, links to pathology and therapeutic target. Autoimmun Rev 3: 368-375, 2004

14. Liu Y, Hong X, Kappler J, Jiang L, Zhang R, Xu L, Pan $\mathrm{CH}$, Martin WE, Murphy RC, Shu HB, Dai S, and Zhang G: Ligand-receptor binding revealed by the TNF family member TALL-1. Nature 423: 49-56, 2003

15. Rahman ZS, Rao SP, Kalled SL, and Manser T: Normal induction but attenuated progression of germinal center responses in BAFF and BAFF-R signaling-deficient mice. J Exp Med 198: 1157-1169, 2003

16. Thompson JS, Schneider P, Kalled SL, Wang L, Lefevre EA, Cachero TG, MacKay F, Bixler SA, Zafari M, Liu ZY, Woodcock SA, Qian F, Batten M, Madry C, Richard Y, Benjamin CD, Browning JL, Tsapis A, Tschopp J, and Ambrose C: BAFF binds to the tumor necrosis factor receptor-like molecule $B$ cell maturation antigen and is important for maintaining the peripheral B cell population. J Exp Med 192: 129-135, 2000

17. Harless SS and Cancro MP: Integrating B cell homeostasis and selection with BAFF. Arch. Immunol Ther Exp 51: 209-218, 2003

18. Oliver AM, Martin F, and Kearney JF: IgMhigh CD21high lymphocytes enriched in the splenic marginal zone generate effector cells more rapidly than the bulk of follicular B Iymphocytes. J Immunol 162: 7198-7207, 1999

19. Shahaf G, Allman D, Cancro MP, and Mehr R: Screening of alternative models for transitional B cell maturation. Int Immunol 16: 1081-1090, 2004

20. Loder F, Mutschler B, Ray RJ, Paige CJ, Sideras P, Torres R, Lamers MC, and Carsetti R: B cell development in the spleen takes place in discrete steps and is determined by the quality of $\mathrm{B}$ cell receptor-derived signals. J Exp Med 190: 75-89, 1999

21. Batten M, Groom J, Cachero TG, Qian F, Schneider P, Tschopp J, Browning JL, and Mackay F: BAFF mediates survival of peripheral immature B lymphocytes. J Exp Med 192: 1453-1465, 2000

22. Rolink AG, Tschopp J, Schneider P, and Melchers F: BAFF is a survival and maturation factor for mouse $B$ cells. J Immunol 32: 2004-2010, 2002

23. Do RK, and Chen-Kiang S: Mechanism of BLyS action in B lymphocyte immunity. Cytokine Growth Factor Rev 13: 19-25, 2002

24. Batten M, Fletcher C, Ng LG, Groom J, Wheway J, Laabi Y, Xin X, Schneider P, Tschopp J, Mackay CR, and Mackay F: TNF deficiency fails to protect BAFF transgenic mice against autoimmunity and reveals a predisposition to B cell lymphoma. J Immunol 172: 812-822, 2004 